\title{
Cyclic Axial-Torsional Deformation Behavior of a Cobalt-Base Superalloy
}

REFERENCE: Bonacuse, P. J. and Kalluri, S., "Cyclic Axial-Torsional Deformation Behavior of a Cobalt-Base Superalloy," Cyclic Deformation. Fracture, and Nondestructive Evaluation of Advanced Materials: Second Volume. ASTM STP 1184, M. R. Mitchell and O. Buck, Edh., American Society for Testing and Materials, Philadelphia, 1994, pp. 204-229.

ABSTRACT: The cyclic, high-temperature detormation behavior of a wrought cobalt-base superalloy, Haynes 188 , is investigaled under combined axial and torsional loads. This is accomplished through the examination of hysteresis loops generated from a biaxial fatigue test program. A high-temperature axial, torsional, and combined axial-torsional fatigue database has been generated on Haynes 188 at $760^{\circ} \mathrm{C}$. Cyclic loading tests have been conducted on uniform gage section tubular specimens in a servohydraulic axial-1orsional test rig. Test control and data acquisition were accomplished with a minicomputer. The fatigue behavior of Haynes 188 at $760^{\circ} \mathrm{C}$ under axial, torsional, and combined axial-torsional loads and the monotonic and cyclic deformation behaviors under axial and torsional loads have been previously reported. In this paper, the cyclic hardening characteristics and typical hysteresis loops in the axial stress versus axial strain, shear stress versus engineering shear strain, axial strain versus engineering shear strain. and axial stress versus shear stress spaces are presented for cyclic in-phase and out-of-phase axial-torsional tests. For in-phase tests, three different values of the proportionality constant, $\lambda$ (the ratio of engineering shear strain amplitude to axial strain amplitude, $\gamma / \varepsilon_{u}$ ), are examined, viz, $0.86,1.73$, and 3.46. In the out-of-phase tests, three different values of the phase angle, $\phi$ (between the axial and engineering shear strain waveforms). are studied, vi $\ldots, 30,60$, and $90^{\circ}$ with $\lambda=1.73$. The cyclic hardening behaviors of all the tests conducted on Haynes 188 at $760^{\circ} \mathrm{C}$ are evaluated using the von Mises equivalent stress-strain and the maximum shear stress-maximum engineering shear strain (Tresca) curves. Comparisons are also made between the hardening behaviors of cyclic axial, torsional, and combined in-phase $\left(\lambda=1.73\right.$ and $\left.\phi=0^{\circ}\right)$ and out-of-phase $(\lambda=1.73$ and $\left.\phi=90^{\circ}\right)$ axial-torsional fatigue tests. These comparisons are accomplished through simple Ramberg-Osgood type stress-strain functions for cyclic, axial stress-strain and shear stress-engineering shear strain curves.

KEYWORDS: axial-torsional loading, multiaxiality, in-phase loading, out-of-phase loading, cyclic deformation. equivalent stress-strain curve, cobalt-base superalloy. clevated temperature

\section{Nomenclature}

$N$ Cycle number

$N$ Cyclic life

$n^{\prime} \quad$ Cyclic axial strain-hardening exponent

$n_{i}^{\prime} \quad$ Cyclic torsional strain-hardening exponent

$E, G$ Young's and shear moduli

$K^{\prime} \quad$ Cyclic axial strength coefficient

$K_{i}^{\prime}$ Cyclic torsional strength coefficient

$\Delta$ Denotes range of the variable

$$
\begin{aligned}
& \text { USR NASA } \\
& N-26-7 M \\
& \text { (c) pमा } \\
& \therefore \text { if } 633
\end{aligned}
$$

NASA-TM-112116

' Research engineer, U.S. Army Rescarch Laboralnry, Vehicle Propulsion Directorate. NASA Lewis Research Center, Cleveland. OH.

'Senior research engineer, NYMA, Inc., NASA lewis Research Center. Cleveland, OH. 
$\gamma, \varepsilon \quad$ Engineering shear and axial strains

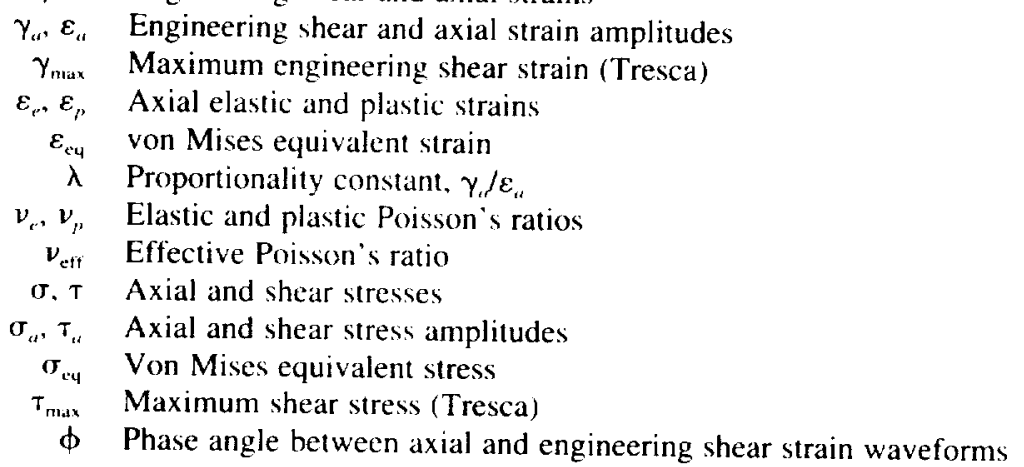

\section{Introduction}

The imperatives of higher efficiency and improved performance in gas turbines require that the rotating speeds, power extraction per turbine stage, and operating temperatures all be increased beyond the current levels. This may mean that the materials used in the hot section are being pushed up to and beyond their recommended usage linits. It is important that the deformation behavior of these materials be understood at temperatures and loading conditions that approximate the service conditions of the component. Design decisions for these materials are currently being made with material properties and databases that have been extrapolated from lower-temperature, uniaxial, fatigue and deformation data. These extrapolated data may imply a behavior that is significantly different from the material's actual response under service conditions.

The cyclic deformation behavior of polycrystalline metallic materials under combined axialtorsional loading conditions has been the subject of several investigations $|1-9|$. These studies were conducted on tubular specimens of low-alloy steels $[1,3,7]$, stainless steels $[1,2,4-8]$, and a superalloy $[9]$ at both room $[1-7,9]$ and elevated $[1,8]$ temperatures. Different types of waveforms, including sinusoidal $[2-9]$, triangular $[1,4,6]$, and trapezoidal $[4-7]$, were employed as command inputs for the axial and engineering shear strains. In this study, the cyclic deformation behavior of a wrought cobalt-base superalloy, Haynes 188 , has been investigated under axial-torsional loading conditions at $760^{\circ} \mathrm{C}$. Haynes 188 is currently used in many aerospace gas turbine and rocket engine applications, e.g., the combustor liner for the T800 turboshaft engine for the RAH-66 Comanche helicopter and the liquid oxygen posts in the main injector of the space shuttle main engine.

The objective of this paper is to disseminate the cyclic deformation data collected in the course of performing high-temperature, axial-torsional fatigue tests on Haynes 188 and to relay some observations about the collected data. Various independent as well as simultaneous combinations of axial and torsional loads were imposed on 36 specimens in the test program. The following axial-torsional deformation results are discussed: (1) the effect of the ratio of the engineering shear strain amplitude to the axial strain amplitude (proportionality constant, $\lambda$ ) on the in-phase (proportional) deformation behavior, and (2) the effect of phase angle ( $\phi$ ) between the axial and engineering shear strains (out-of-phase or non-proportional) on the cyclic and stabilized stress response. The cyclic hardening under different axial-torsional loading conditions is presented through plots of hysteresis loops at several cyclic increments and plots of stress range versus number of cycles. In addition, the presentation format consists of normalized plots of stable (near half-life) axial and torsional hysteresis loops as well as normalized plots of the axial strain versus engineering shear strain and the axial stress versus shear stress for 
the near half-life conditions. Also, results of regressed fits to the Ramberg-Osgood equation with the stabilized cyclic deformation data under various axial-torsional loading conditions are reported. The stabilized deformation behaviors of the in- and out-of-phase axial-torsional experiments are compared.

All tests described in this paper were conducted in air at $760^{\circ} \mathrm{C}$. This temperature was chosen because Haynes 188 displays a marked drop in ductility at this temperature $[10 \mid$. This ductility minimum is most likely due to complex interactions between mobile solute atoms and dislocations. Understanding the deformation behavior at this temperature will advance our ability to assess this material's usefulness in advanced gas turbine applications.

\section{Experimental Program}

The cobalt-base superalloy, Haynes 188 , was supplied by a commercial vendor in the form of hot-rolled. solution-annealed round bars with a nominal diameter of $50.8 \mathrm{~mm}$ (manufactured to Aerospace Material Specification 5772A). The chemical composition of the superalloy in weight percent is as follows: $<0.002 \mathrm{~S} ; 0.002 \mathrm{~B} ; 0.012 \mathrm{P} ; 0.1 \mathrm{C} ; 0.4 \mathrm{Si} ; 0.034 \mathrm{La} ; 0.75 \mathrm{Mn}$; $1.24 \mathrm{Fe} ; 13.95 \mathrm{~W} ; 21.84 \mathrm{Cr} ; 22.43 \mathrm{Ni}$, with cobalt making up the balance. The grains in the supplied material were equiaxed and ranged in size from 45 to $65 \mu \mathrm{m}$. The specifications for machining the specimens were explicitly designed to minimize surface work hardening. No post machining heat treatment was performed on the tubular specimens.

Thin-walled tubular specimens with a nominal outer diameter of $26 \mathrm{~mm}$, a nominal inner diameter of $22 \mathrm{~mm}$, and a nominal gage length of $25 \mathrm{~mm}$ (Fig. 1) were used in all experiments. The tubular specimens in the axial-torsional test program were heated to the test temperature of $7600^{\circ} \mathrm{C}$ using a $10-\mathrm{kHz}, 10-\mathrm{kW}$ induction heating system with a three-coil (each of the coils is independently moveable) fixture. In all tests, the temperature in the gage section was maintained to within $\pm 7^{\circ} \mathrm{C}$ of the control temperature. A servohydraulic axial-torsional load frame capable of $\pm 223 \mathrm{kN}$ of axial load and $\pm 2.26 \mathrm{kN}-\mathrm{m}$ of torque was used in all experiments. A commercial, water-cooled, axial-torsional extensometer was employed for strain measurement. Further detail on the testing equipment can be found in Refs 11 to 13.

Data acquisition and test control were accomplished with a minicomputer and associated electronic hardware. Detailed information on the data acquisition and control hardware and software for the cyclic axial-torsional experiments can be found in Ref 13. Data were acquired at 500 points per loading cycle to ensure that significant, high-rate deformation phenomenon and the peak stresses and strains were accurately acquired.

Constant strain-rate (triangular) axial and/or engineering shear strain waveforms were imposed on all specimens. The frequency of both of the command waveforms was $0.1 \mathrm{~Hz}$ for all tests; therefore, the strain rate from test to test varied depending on the amplitudes of the strain waveforms. The difference in the strain rates between the smallest and the largest amplitude tests was, at most, a factor of 7 . Because the differences in strain rates were relatively small, little or no strain rate effect on the deformation behavior is expected in the tests performed. The engineering shear strain at the mean radius of the tubular specimen was controlled in all the experiments that had an imposed engineering shear strain. In calculating the shear stress at the mean radius of the specimen, the shear stress was assumed to be uniformly distributed through the thickness of the tubular specimen. In all experiments, the test control software incorporated a graduated five-cycle load up. This allowed for better test control at the onset of the serrated yielding behavior that is often displayed by Haynes 188 when large plastic strains are present. In almost every case this five-cycle load up resulted in some initial plastic deformation in the specimens; therefore, some initial hardening was introduced before the first cycle data were collected.

The test matrix of the axial-torsional test program is shown in Table 1 . Five different values 


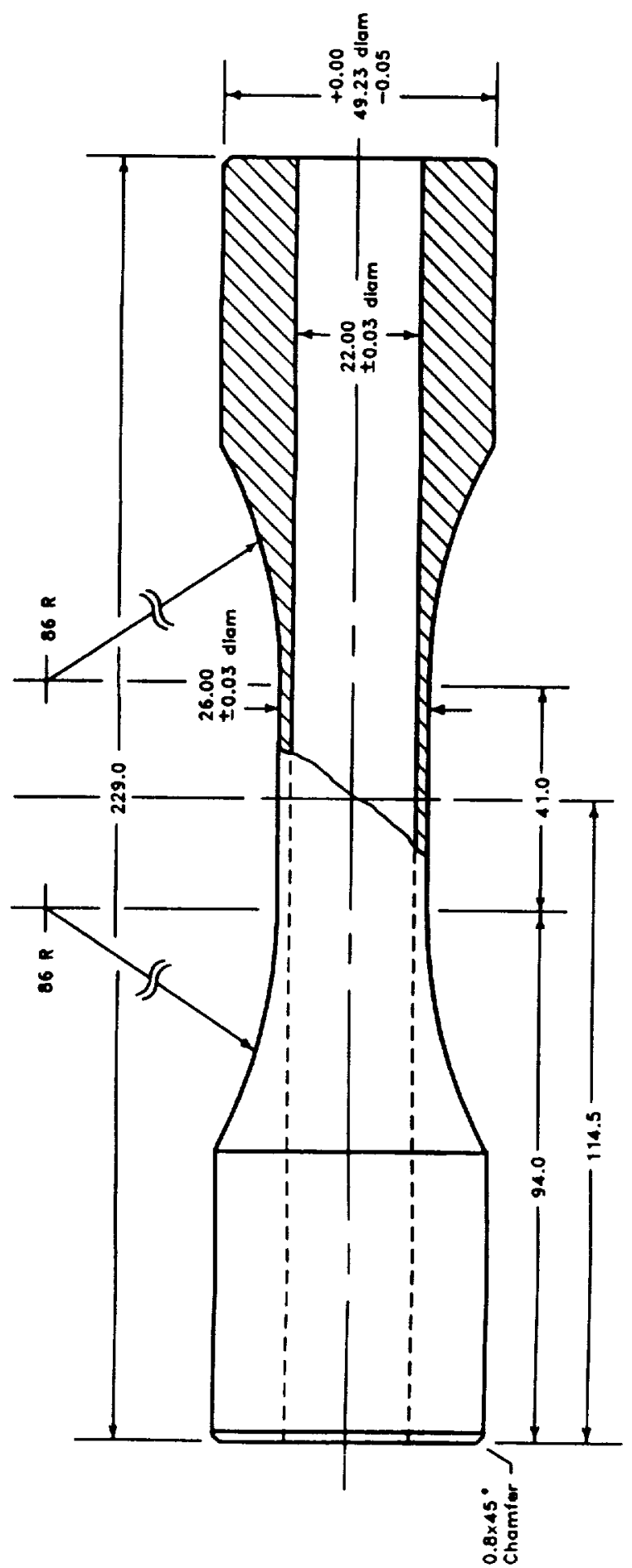

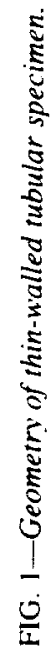

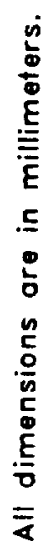


TABLE 1-Axial-torsional test matrix for Haynes 188 at $760^{\circ} \mathrm{C}$.

\begin{tabular}{rccccc}
\hline \multicolumn{5}{c}{$\lambda$} & \multicolumn{1}{c}{} \\
\hline$\phi$ & 0 & 0.86 & 1.73 & 3.46 & $\infty$ \\
\hline $0^{\circ}$ & 7 & 2 & 6 & 2 & 7 \\
$30^{\circ}$ & $\cdots$ & $\cdots$ & 1 & $\ldots$ & $\ldots$ \\
$60^{\circ}$ & $\cdots$ & $\cdots$ & 2 & $\cdots$ & $\ldots$ \\
$90^{\circ}$ & $\cdots$ & $\cdots$ & $9^{a}$ & $\cdots$ & $\cdots$ \\
\hline
\end{tabular}

"Two tests were performed with sinusoidal strain command waveforms.

of the proportionality constant, $\lambda$, and four phase angles, $\phi$, have been investigated in the axialtorsional experiments. The number of tests conducted for each test condition, which is given by a set of $\lambda$ and $\phi$ values, is shown in Table I. In Fig. 2, a simple schematic is presented of the imposed strains during an in-phase and an out-of-phase axial-torsional fatigue test.

\section{Results}

The effect of strain cycling on the shapes of the hysteresis loops is illustrated in Figs. 3 to 6. Axial and torsional loops at 1, 10, 100, and 1000 cycles are plotted for cyclic axial-torsional experiments performed with phase angles, $\phi$, of $0,30,60$, and $90^{\circ}$. In all cases, Haynes 188 exhibited cyclic strain hardening, which is characterized by an increase in the stress range and an associated reduction in the width of the hysteresis loop.

To facilitate direct comparison of the axial and shear cyclic hardening rates of specimens that were subjected to in-phase (proportional) strain paths with different ratios of engineering shear to axial strain amplitudes, the stress ranges were normalized by the first cycle's (after the five-cycle load up) stress range. Plots of the normalized axial component of the in-phase cyclic stresses versus the number of cycles and the normalized shear component of the in-phase cyclic stresses versus the number of cycles are shown in Figs. 7 and 8 . For the axial component of stress, all the in-phase axial-torsional tests exhibited a similar cyclic hardening rate, which was

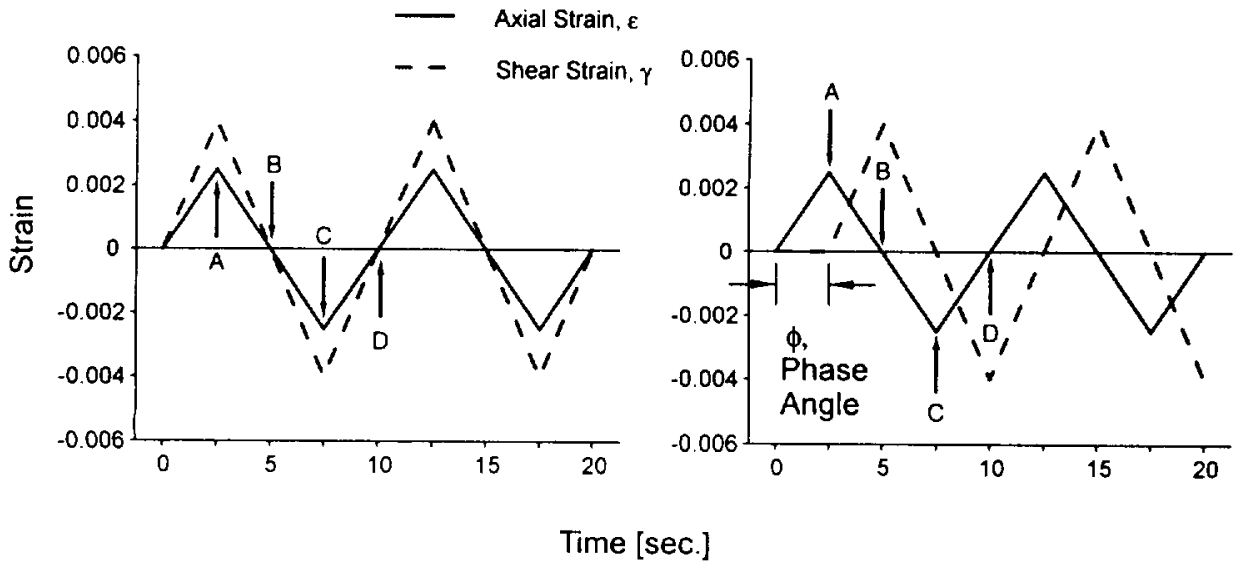

FIG. 2-Schematic of loading naveforms for axial-torsional in-phase and out-of-phase tests. 


\section{Axial Hysteresis Loop}

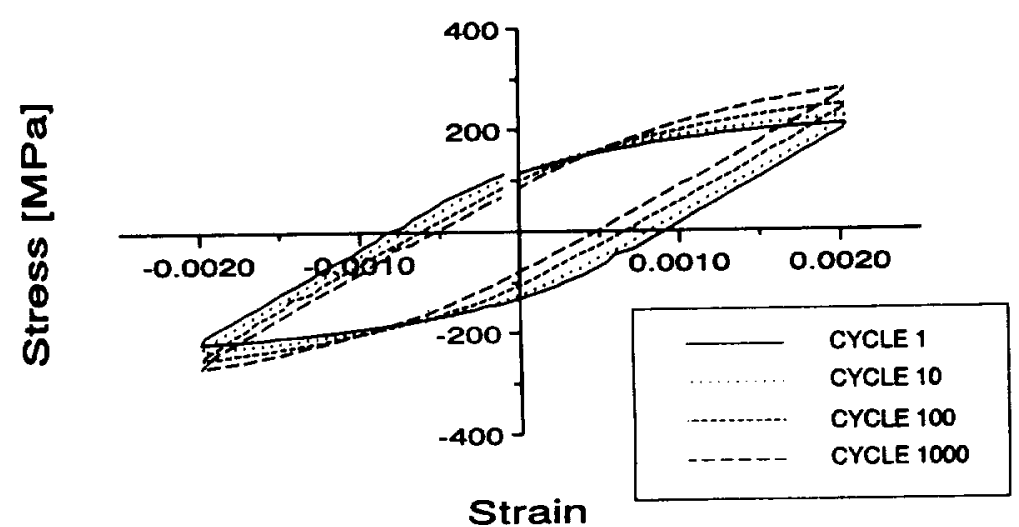

Torsional Hysteresis Loop

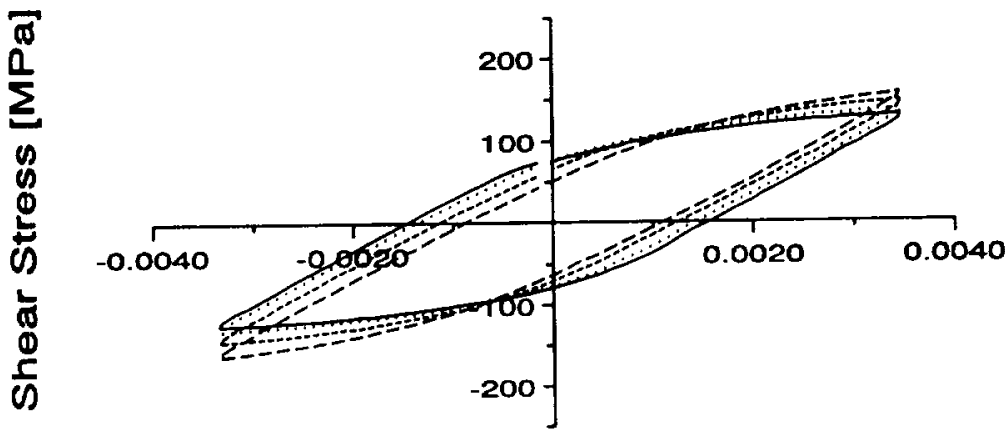

\section{Shear Strain}

FIG. 3-Evolution of axial and torsional hysteresis loops, $\lambda=1.73, \phi=0^{\circ}$.

lower than that observed in the axial test. For the shear component of stress, all the in-phase tests exhibited a cyclic hardening rate that was similar to the torsional test.

The cyclic hardening rates of specimens subjected to the same nominal axial and engineering shear strain amplitudes, with phase angles between the axial and torsional command waveforms of $0,30,60$, and $90^{\circ}$, are compared in Figs. 9 and 10. In these figures the axial and shear stress ranges are plotted against the number of cycles. Both the axial and shear stress components clearly indicate higher first cycle hardening as the phase angle, $\phi$, increases from 0 to $90^{\circ}$. This pattern of increased hardening with phase angle is maintained throughout the life of the outof-phase tests. In plotting the near half-life hysteresis loops from the out-of-phase tests, the stress and strain components were normalized with half the range (amplitude) of the corre- 


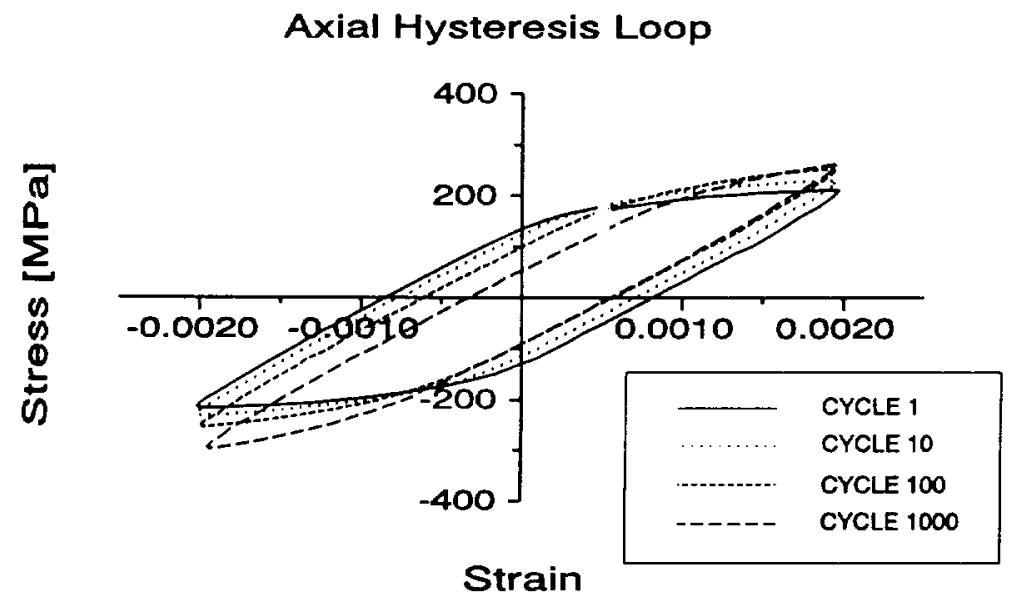

Torsional Hysteresis Loop

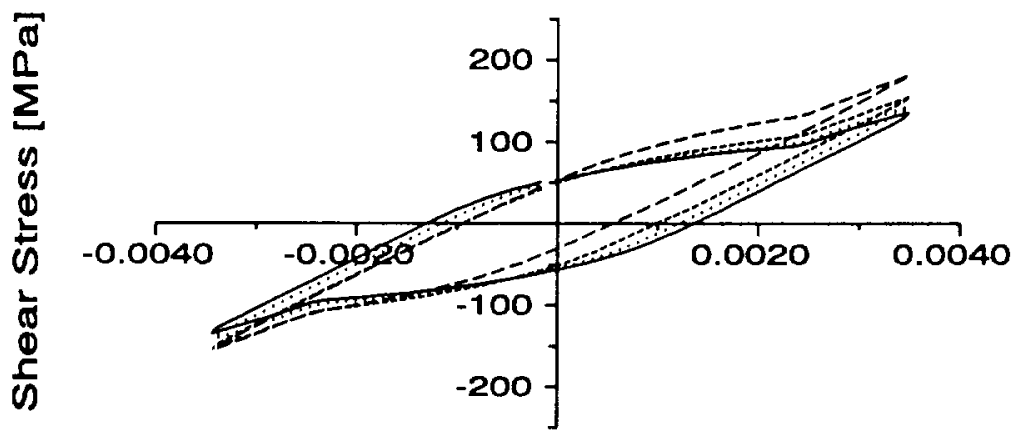

Shear Strain

FIG. 4-Evolution of axial and torsional hysteresis ioops, $\lambda=1.73, \phi=30^{\circ}$.

sponding variable so that the shapes of the hysteresis loops for different $\phi$ values could be compared. By normalizing the variables, the isotropic hardening effects are concealed so that the kinematic effects can be compared directly. The maximum and minimum values of the strains and stresses in the near half-life axial and torsional loops are listed in Table 2. Figures 11 through 14 are the near half-life, normalized, axial $\left(\sigma / \sigma_{a}\right.$ versus $\left.\varepsilon / \varepsilon_{u}\right)$, and torsional $\left(\tau / \tau_{a}\right.$ versus $\gamma / \gamma_{a}$ ) hysteresis loops from four specimens, which were subjected to the same nominal axial and engineering shear strain amplitudes but with four different phase angles $(\phi)$ between the strain waveforms. Also displayed in each figure are the normalized plots of the axial strain $\left(\varepsilon / \varepsilon_{u}\right)$ versus the engineering shear strain $\left(\gamma / \gamma_{u}\right)$ and the axial stress $\left(\sigma / \sigma_{u}\right)$ versus the shear stress $\left(\tau / \tau_{u}\right)$. The normalized axial strain-engineering shear strain plots display the strain path imposed on the specimen. The labels A, B, C, and D in Fig. 2 illustrate where each of the strain 
Axial Hysteresis Loop



Strain

\section{Torsional Hysteresis Loop}

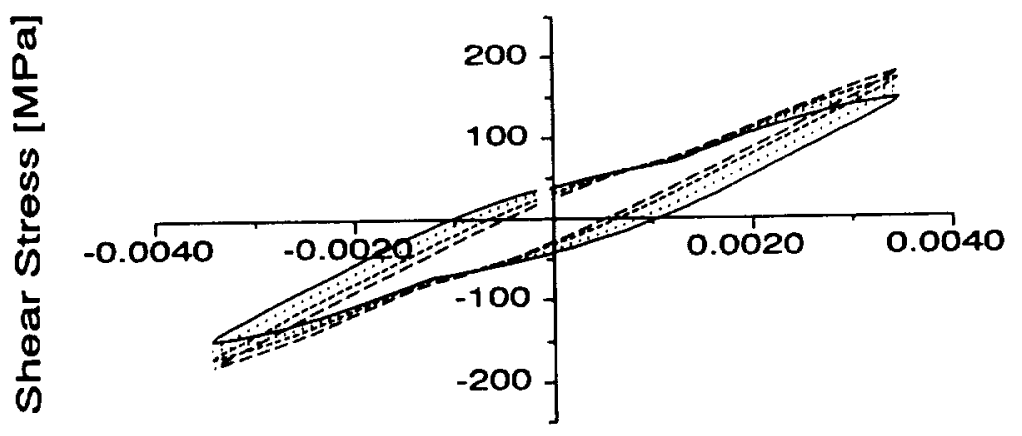

\section{Shear Strain}

FIG. 5-Evolution of axial and torsional hysteresis loops, $\lambda=1.73, \phi=60^{\circ}$.

reversals and zero crossings occur for the axial strain. The labels are repeated at the corresponding points in the normalized figures (Figs. 11-14). The small discontinuities seen in the normalized axial strain versus engineering shear strain and the normalized axial stress versus shear stress plots are due to a seal friction problem in the axial actuator of the test rig, which resisted all attempts of compensation.

For each axial-torsional test conducted, the von Mises equivalent stress, von Mises equivalent strain, the maximum shear stress, and the maximum engineering shear strain (Tresca stress and strain) were computed from the near half-life hysteresis loop data. For each of these quantities, the calculation was performed at each of the 500 collected data points around the cycle to determine the maximum and minimum values. Performing the equivalent and maximum shear calculations in this way was not specifically necessary for the case of the in-phase tests, but it was required for the oull-of-phase experiments because the maximum values of the equivalent 


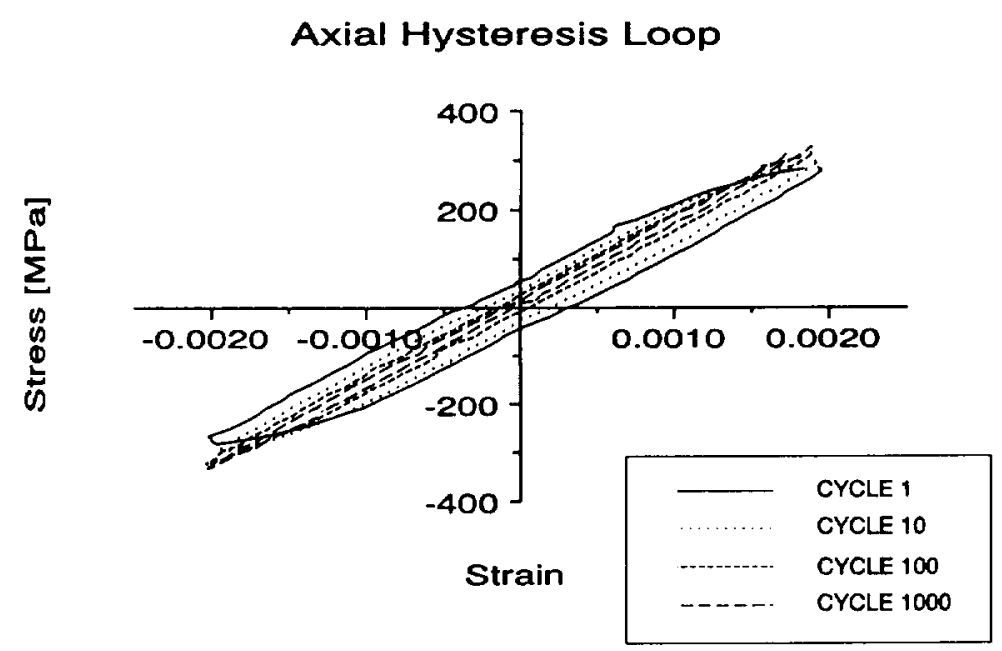

Torsional Hysteresis Loop

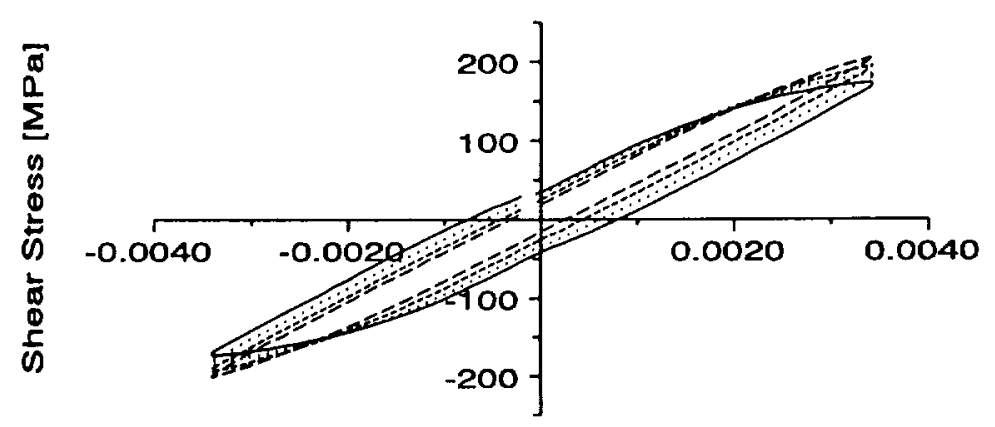

\section{Shear Strain}

FIG. 6-Evolution of axial and torsional hysteresis loops, $\lambda=1.73, \phi=90^{\circ}$. 


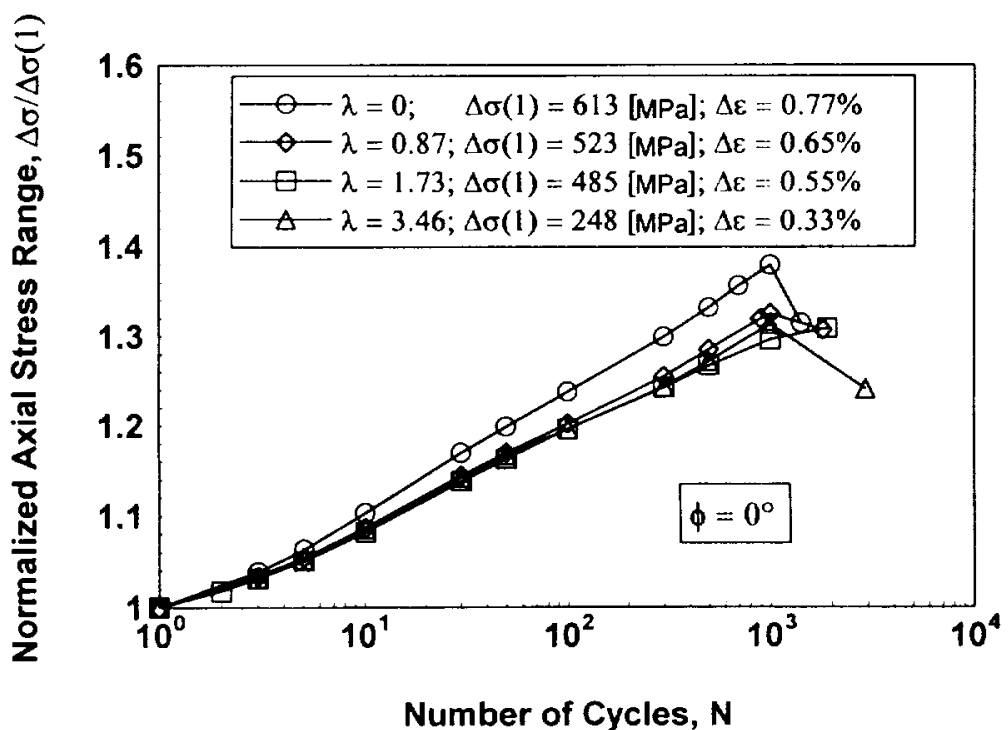

FIG. 7-Cyclic variation of the normalized (to first cycle axial stress range) axial stress range for in-phase experiments.

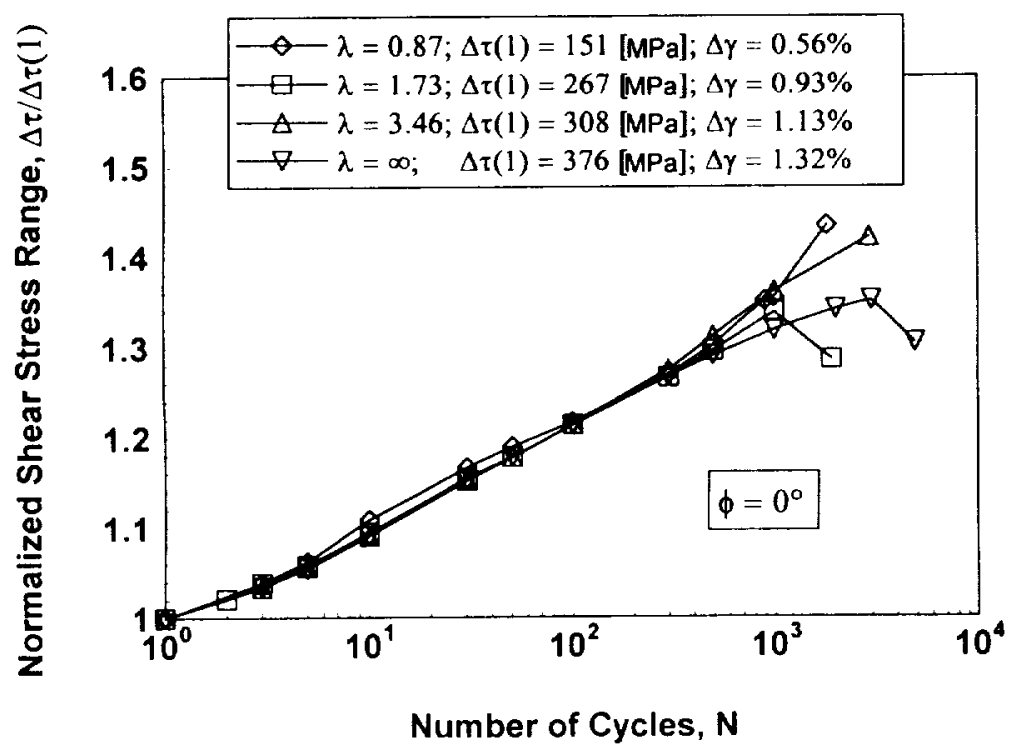

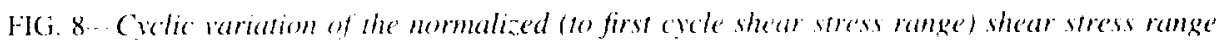
for in-phase experiments. 


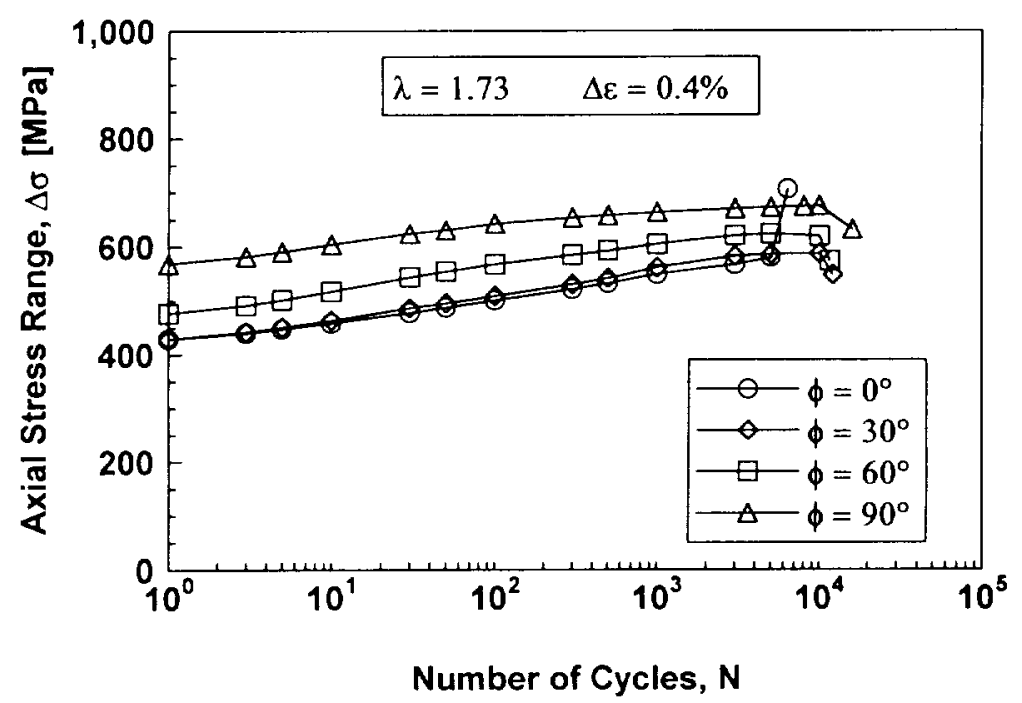

FIG. 9-Cyclic variation of axial stress range for out-of-phase experiments.



FIG. 10-Cvelic variation of shear stress range for out-of-phase experiments. 
TABLE 2-Maximum and minimum strains and stresses in the near half-life axial and torsional hysteresis loops. $\lambda=1.73$.

\begin{tabular}{|c|c|c|c|c|c|c|c|c|c|c|}
\hline \multirow[b]{2}{*}{$\phi$} & \multirow[b]{2}{*}{$N$} & \multirow[b]{2}{*}{$N$} & \multicolumn{2}{|c|}{$\underset{\%}{\text { Axial Strain, } \varepsilon \text {, }}$} & \multicolumn{2}{|c|}{$\begin{array}{c}\text { Axial Stress, } \\
\sigma, \mathrm{MPa}\end{array}$} & \multicolumn{2}{|c|}{$\begin{array}{c}\text { Engineering } \\
\text { Shear Strain, } \gamma \text {. }\end{array}$} & \multicolumn{2}{|c|}{$\begin{array}{c}\text { Shear Stress, } \\
\tau, \mathrm{MPa}\end{array}$} \\
\hline & & & $\operatorname{Max}$ & Min & $\operatorname{Max}$ & Min & Max & Min & $\operatorname{Max}$ & Min \\
\hline $0^{\circ}$ & 3000 & 6261 & 0.21 & -0.20 & 287 & -279 & 0.35 & -0.34 & 163 & -168 \\
\hline $30^{\circ}$ & 6000 & 12136 & 0.19 & -0.20 & 277 & -309 & 0.35 & -0.35 & 186 & -171 \\
\hline $60^{\circ}$ & 6000 & 11564 & 0.19 & -0.19 & 313 & -310 & 0.35 & -0.35 & 188 & -187 \\
\hline $90^{\circ}$ & 8000 & 16003 & 0.19 & -0.20 & 345 & -329 & 0.34 & -0.34 & 211 & -204 \\
\hline
\end{tabular}

or maximum shear stress and strain may not coincide with peak axial or torsional stresses and strains in the out-of-phase experiments.

An effective Poisson's ratio $\left(\nu_{\text {etf }}\right)$ was computed based on the measured axial stresses and strains. At each point around the hysteresis loop, $v_{\text {eff }}$ was computed with the following equation

$$
v_{\mathrm{eff}}=\left[\frac{\varepsilon_{t} \nu_{e}+\varepsilon_{\mu, \nu} \nu_{p}}{\varepsilon}\right]
$$

where

$$
\varepsilon_{\varepsilon}=\sigma / E
$$

and

$$
\varepsilon_{i}=\varepsilon-\varepsilon_{r}
$$

Values of $E=170.2 \mathrm{GPa}, G=64.4 \mathrm{GPa}$, and $\nu_{\varphi}=0.321$, determined from the averages of all measured values of Young's and shear moduli, were used in computing $v_{\text {etr }}$. A value of 0.5 was assumed for $v_{p}$. For the seven tests performed with $\lambda=\infty$ (torsional loading only), a value of 0.5 was assumed for $v_{\mathrm{et}}$. For axial-torsional loading, the von Mises equivalent stresses and strains were determined by

$$
\begin{gathered}
\varepsilon_{\mathrm{rq}}=\sqrt{\varepsilon^{2}+\frac{3}{4} \frac{\gamma^{2}}{\left(1+\nu_{\mathrm{cft}}\right)^{2}}} \\
\sigma_{\mathrm{eq}}=\sqrt{\sigma^{2}+3 \tau^{2}}
\end{gathered}
$$

The maximum shear stress and maximum engineering shear strain (Tresca stresses and strains) within a given cycle of loading for the axial-torsional tests were determined according to

$$
\begin{gathered}
\gamma_{\max }=\sqrt{\left(1+v_{\text {etf }}\right)^{2} \varepsilon^{2}+\gamma^{2}} \\
\tau_{\max }=\frac{1}{2} \sqrt{\sigma^{2}+4 \tau^{2}}
\end{gathered}
$$

The maximum and minimum of these calculated values were stored and used to calculate the range and amplitude of each variable (this was done to prevent any bias due to mean stresses 

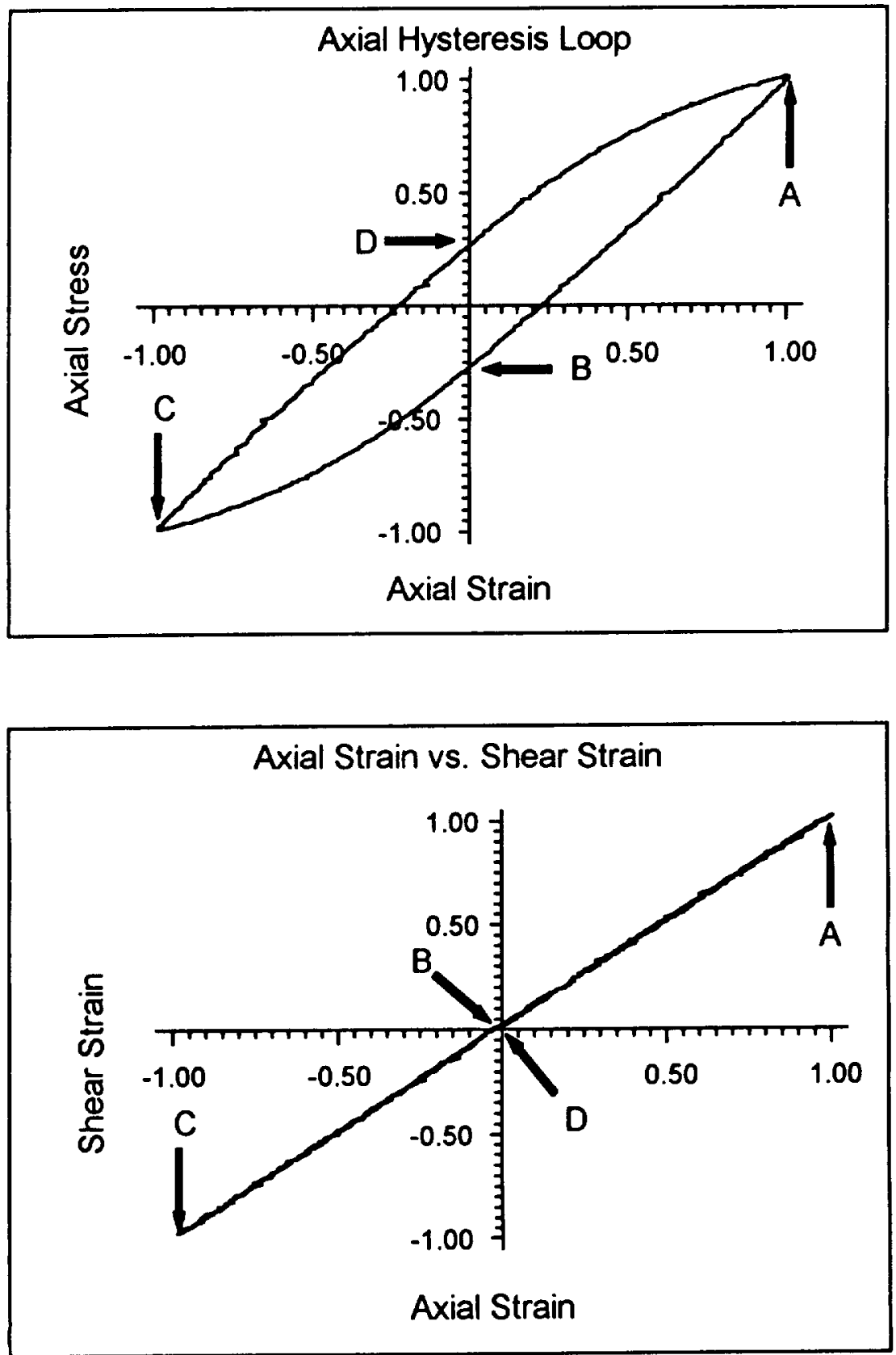

FIG. 11 -Normalized loops, $\lambda=1.73, \phi=0^{\circ}$ : axial hysteresis loop, torsional hysteresis loop, axial strain versus engineering shear strain, and axial stress versus shear stress. 

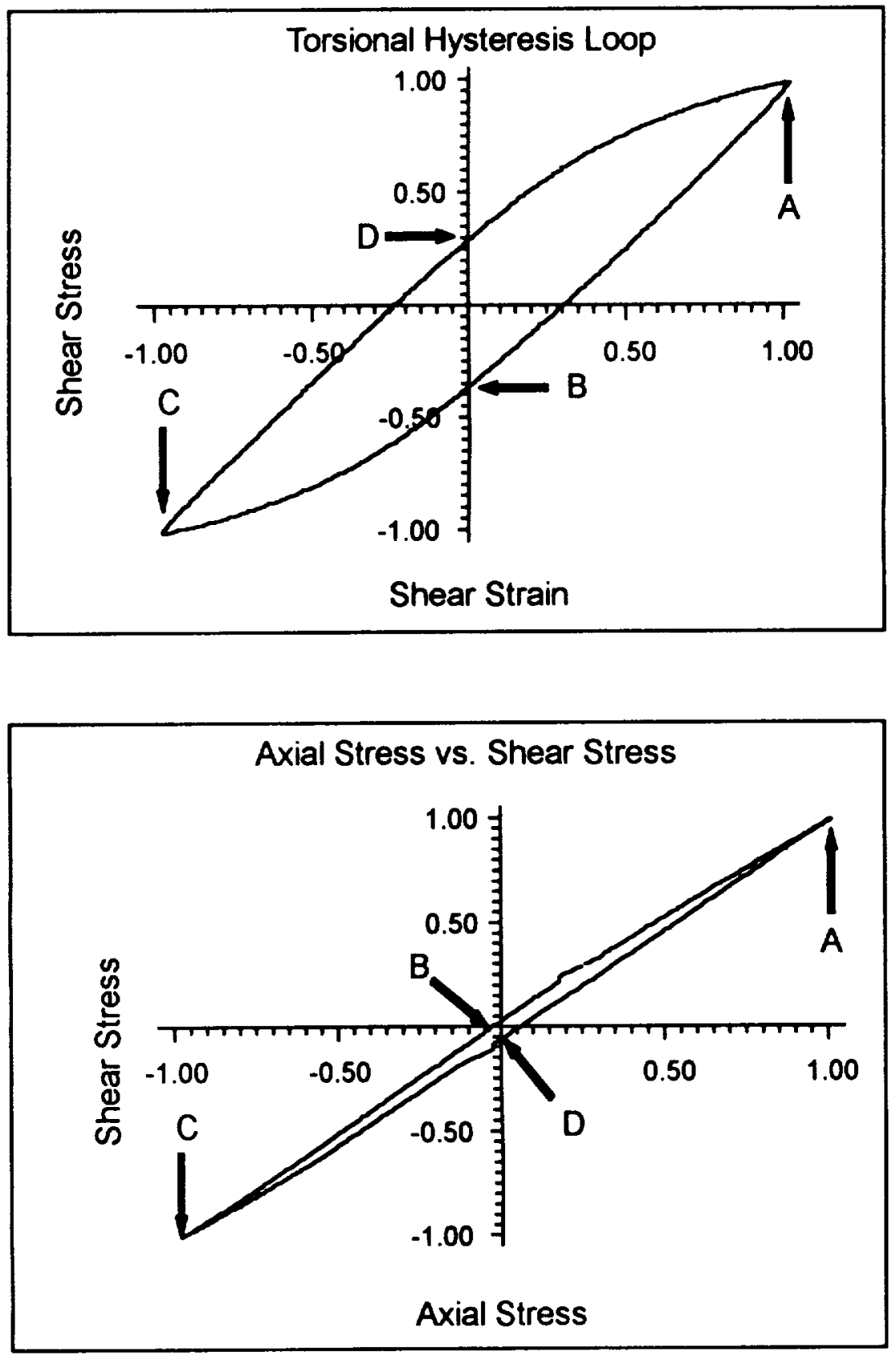

FIG. $11-$ Continued. 



FIG. 12-Normalized loops, $\lambda=1.73, \phi=30^{\circ}$ : axial hysteresis loop, torsional hysteresis loop, axial strain versus engineering shear strain, and axial stress versus shear stress. 

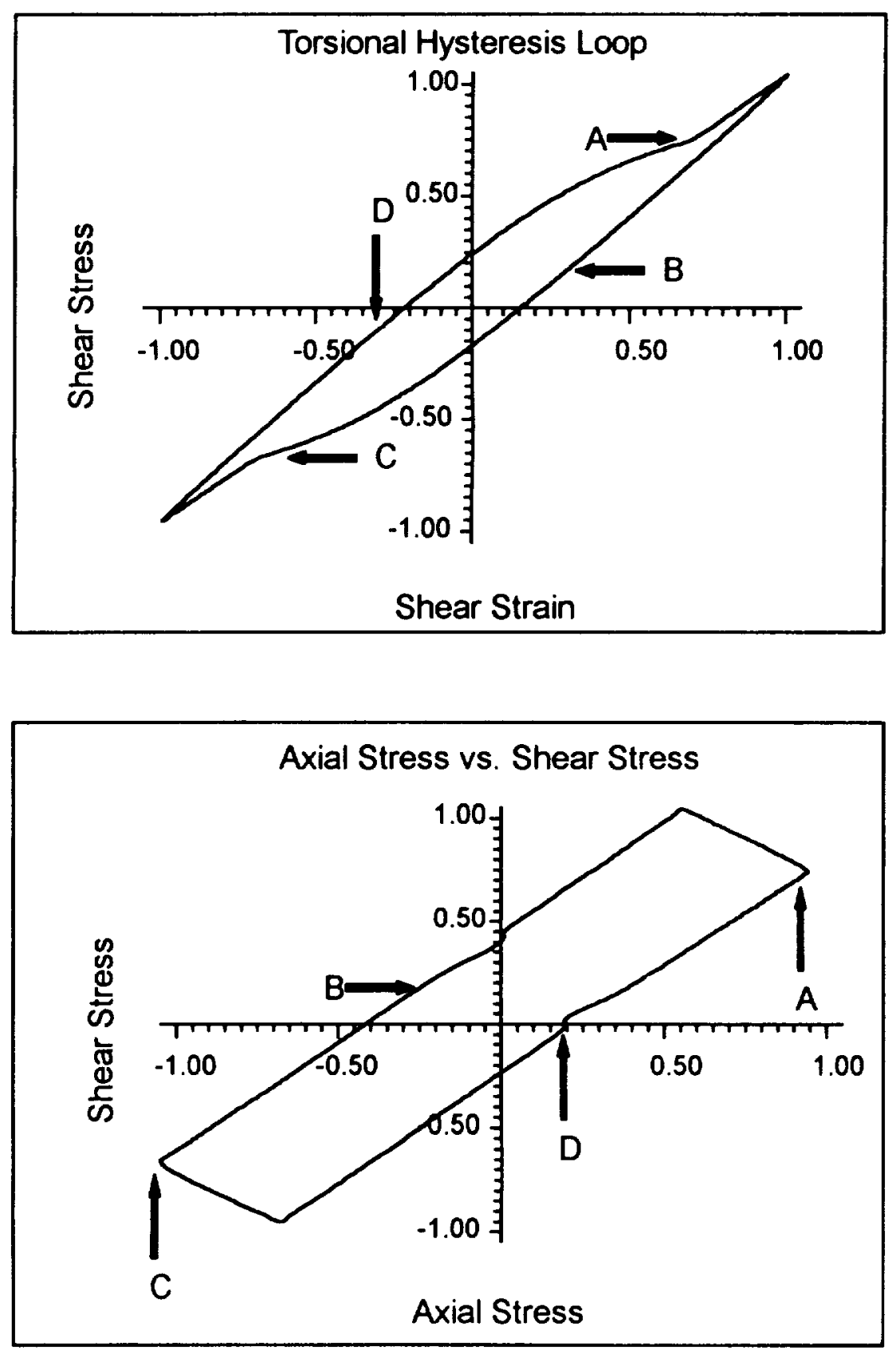

FIG. 12--Continued. 

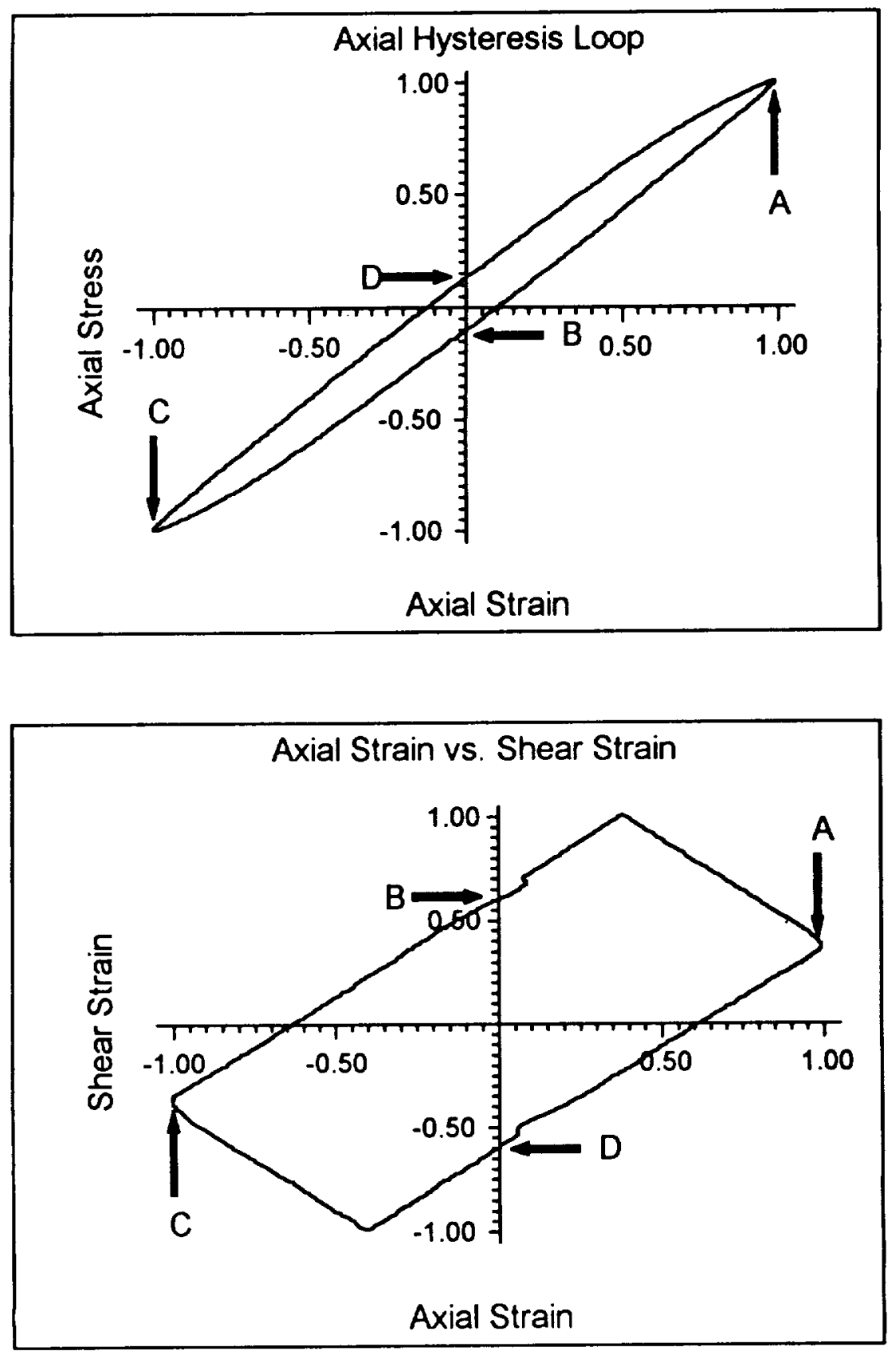

FIG 13-Nomalized loops, $\lambda=1.73, \phi=60^{\circ}$ : axial hysteresis loop, torsional hysteresis loop. axial strain lersus engineering shear strain. and axial stress versus shear stress. 

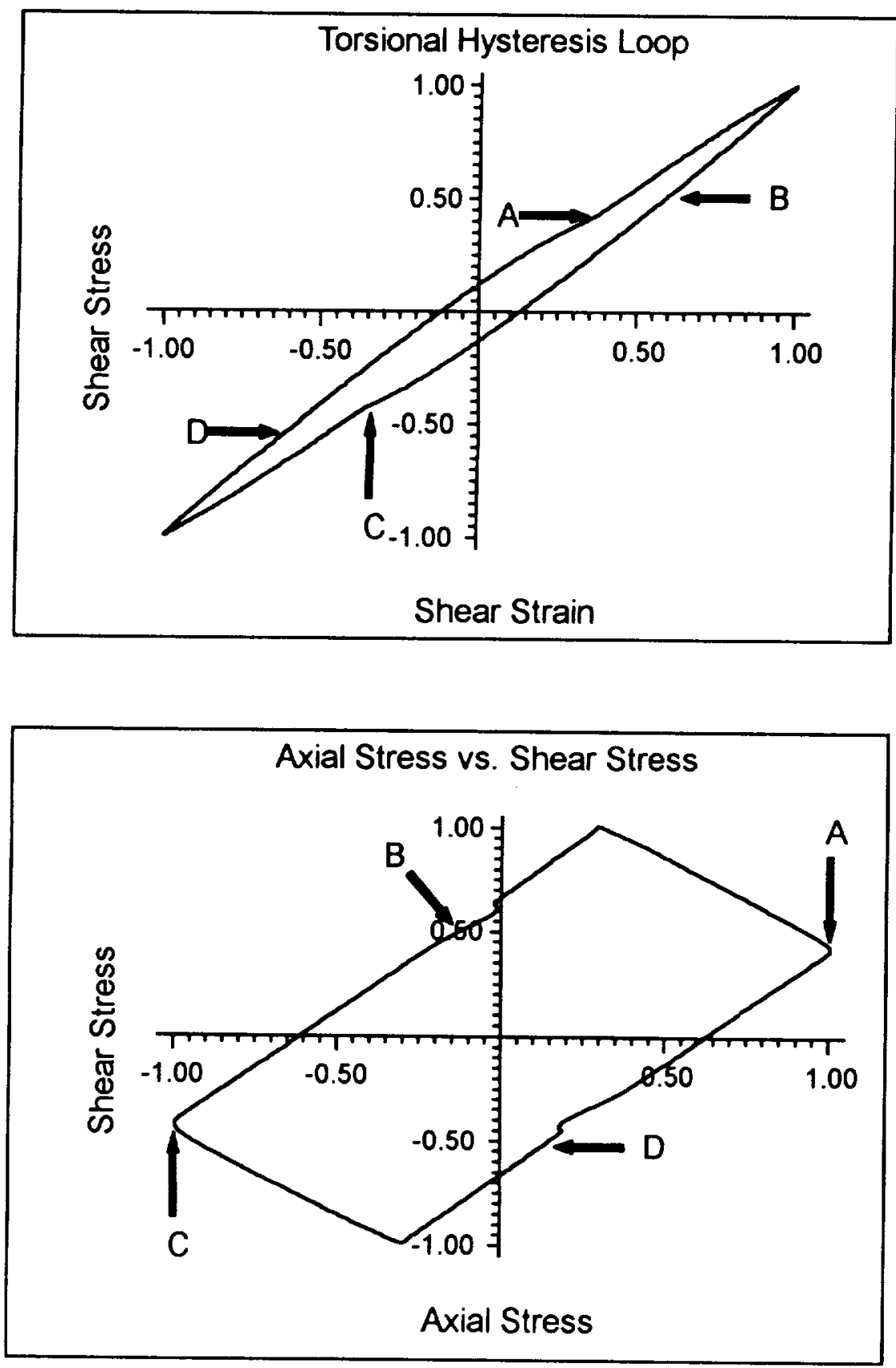

FIG. 1.3-Continued. 

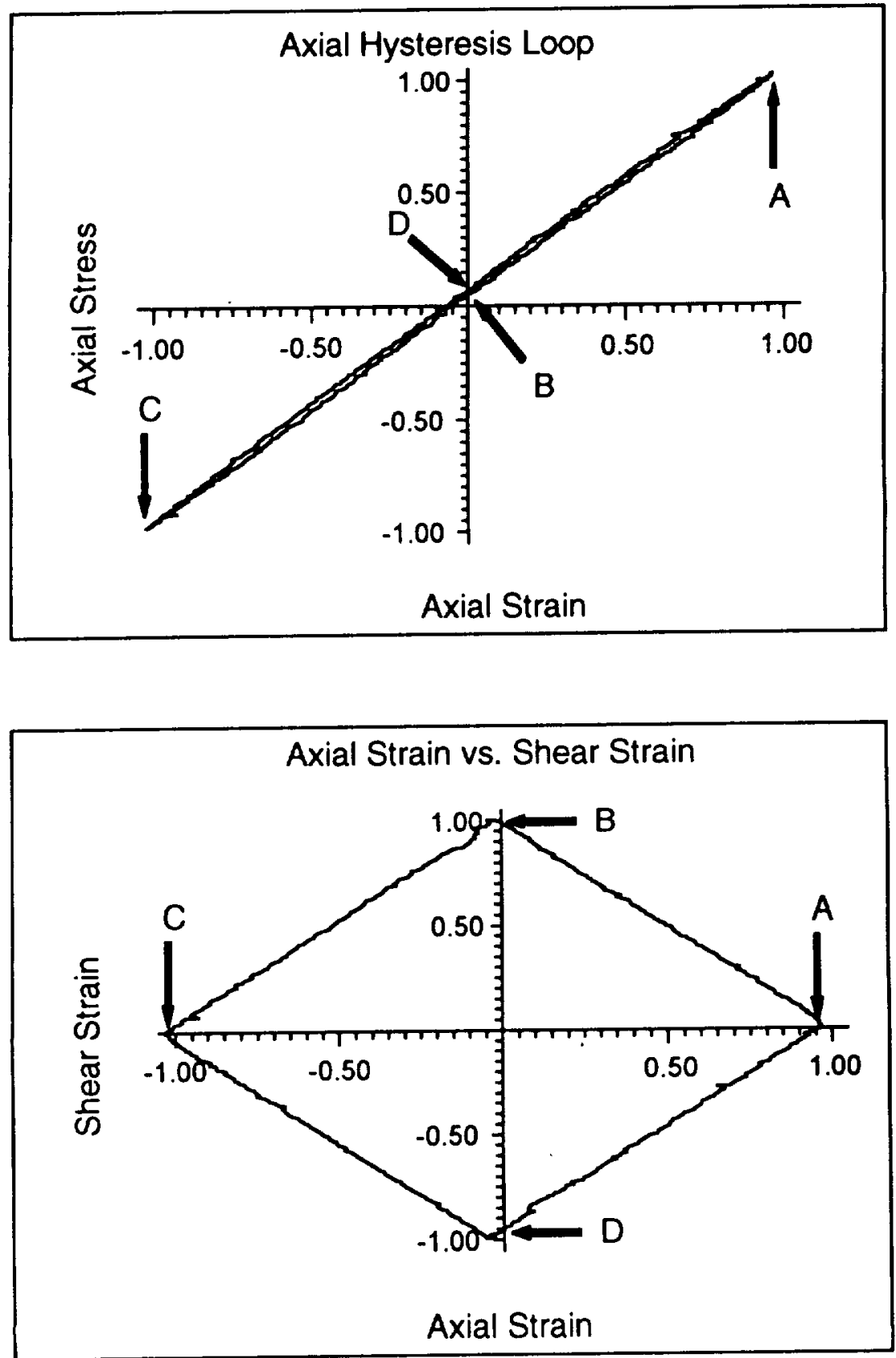

FIG. 14--Normalized loops, $\lambda=1.73, \phi=90^{\circ}$ : axial hysteresis loop, torsional hysteresis loop. axial strain versus engine'ering shear strain, and axial stress versus shear stress. 

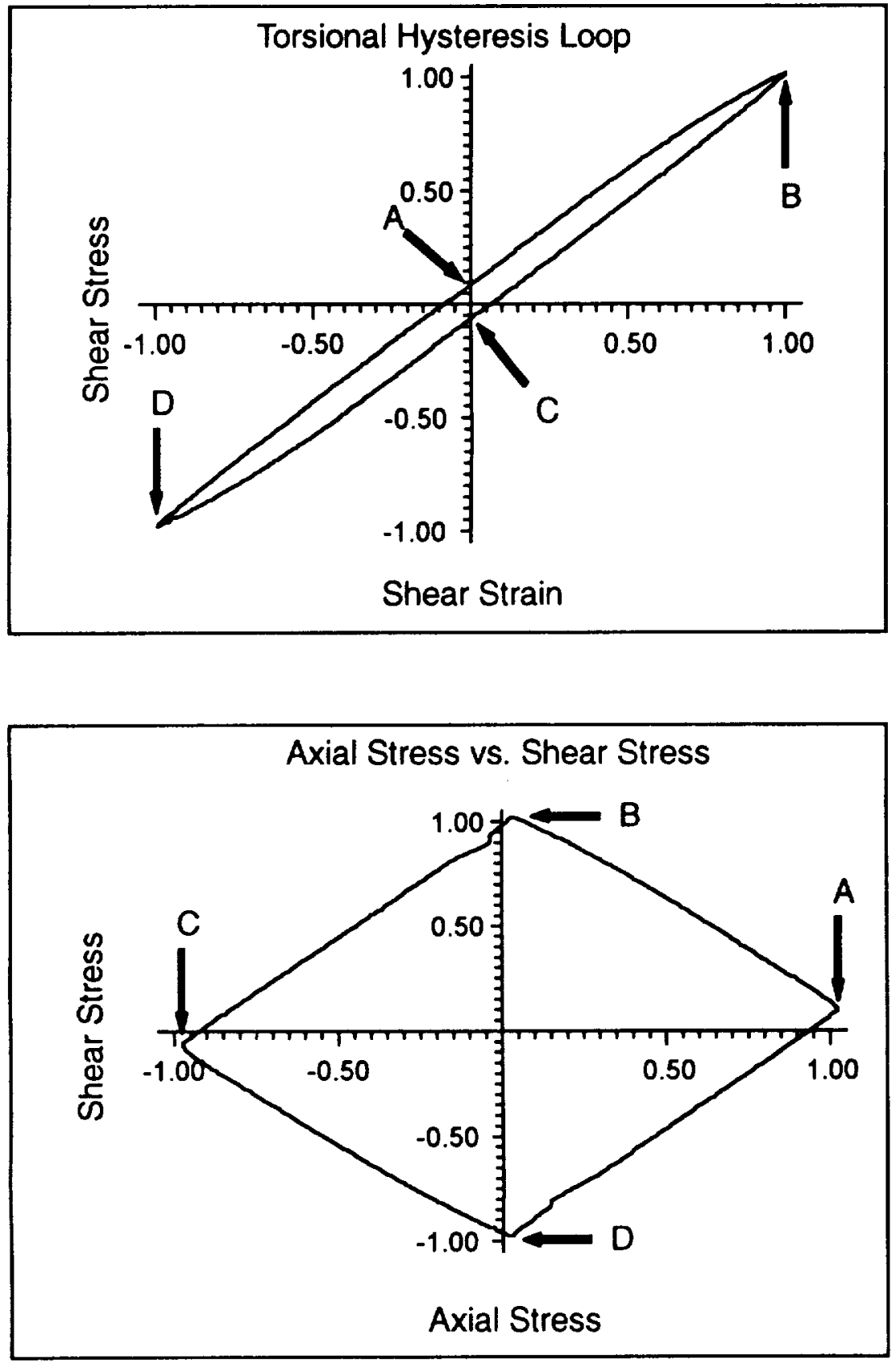

FIG. 14-Continued. 


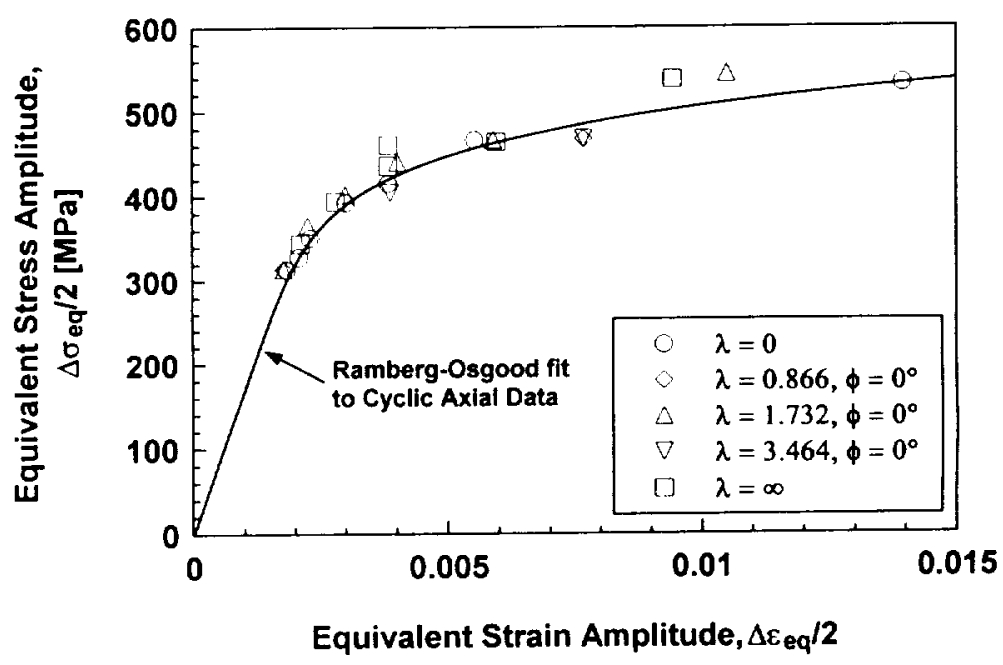

FIG. 15--Equivalent stress-strain (von Mises) data: in-phase experiments.

or strains). The sign (positive or negative) of each of the calculated values was determined by the sign of quantity that had the larger absolute magnitude. The results of these computations for the in-phase experiments are shown in Figs. 15 (von Mises) and 16 (Tresca). Out-of-phase test results are shown in Figs. 17 (von Mises) and 18 (Tresca). In the von Mises equivalent stress-strain figures, a curve representing the Ramberg-Osgood equation fit to the cyclic axial data $(\lambda=0)$ is also plotted. In the maximum shear stress versus maximum engineering shear strain figures, a curve representing the Ramberg-Osgood equation fit to the cyclic torsional data $(\lambda=\infty)$ is shown. In all four plots both the cyclic axial $(\lambda=0)$ and cyclic torsional $(\lambda=\infty)$ data are also displayed. Some axial strain ratchetting ${ }^{7}$ was observed in the torsional experiments $(\lambda=\infty)$, but it was not used to compute the von Mises or Tresca strains.

The Ramberg-Osgood stress-strain curve obtained from the cyclic axial data seems to represent the in-phase axial-torsional data better than the maximum shear stress-maximum engineering shear strain curve obtained from the cyclic torsional data. Both the von Mises equivalent stress-strain curve and the maximum shear stress-maximum engineering shear strain curve underestimate the cyclic hardening in the out-of-phase axial-torsional tests where $\phi=90^{\circ}$. Two out-of-phase axial-torsional tests with $\phi=90^{\circ}$ were conducted with sinusoidal waveforms also at a frequency of $0.1 \mathrm{~Hz}$. The cyclic hardening in these tests was similar to the cyclic hardening in tests conducted with triangular waveforms (Figs. 17 and 18), indicating that the effect of waveform (or small differences in strain rate) is not significant for Haynes 188 at $760^{\circ} \mathrm{C}$

'Similar axial strain ratchetting has been observed under torsional loading by several researchers [1417|. In the majority of the torsional tests $(\lambda=\infty)$ on Haynes 188 at $760^{\circ} \mathrm{C}$, the mean axial ratchetting strain was positive and increased in magnitude with the number of cycles. However, for all the torsional experiments, the magnitude of the mean axial ratchetting strain near half-life was relatively small compared to the amplitude of the imposed engineering shear strain. Therefore, the axial ratchetting strain was not used in computing the von Mises and Tresca strains for the torsional experiments. 




FIG. 16-Maximum shear stress-engineering shear strain (Tresca) data: in-phase experiments.

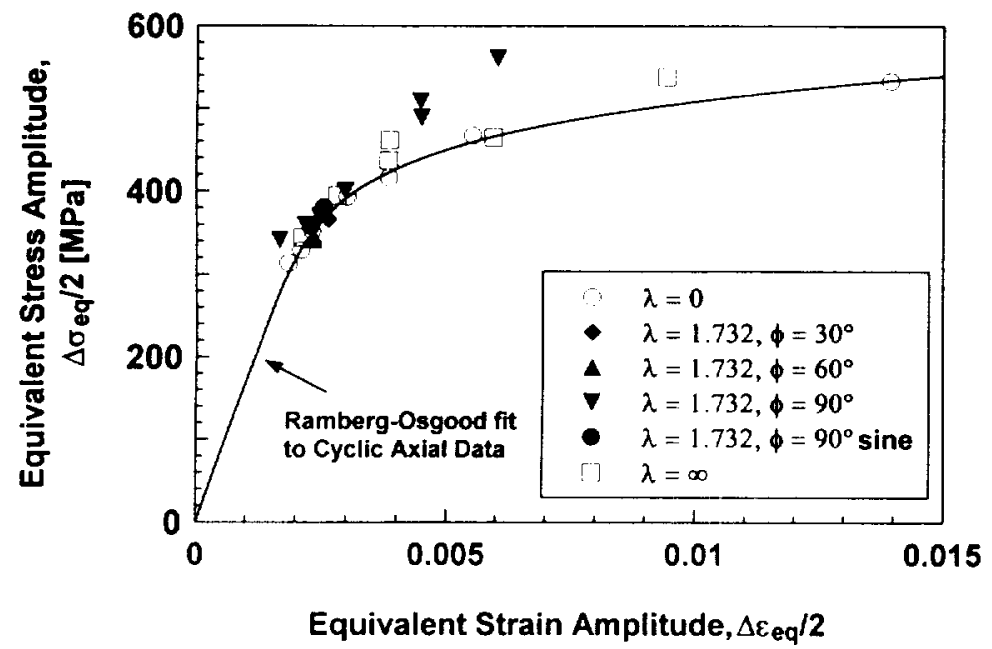

FIG. 17-Equivalent stress-strain (von Mises) data: out-of-phase experiments. 


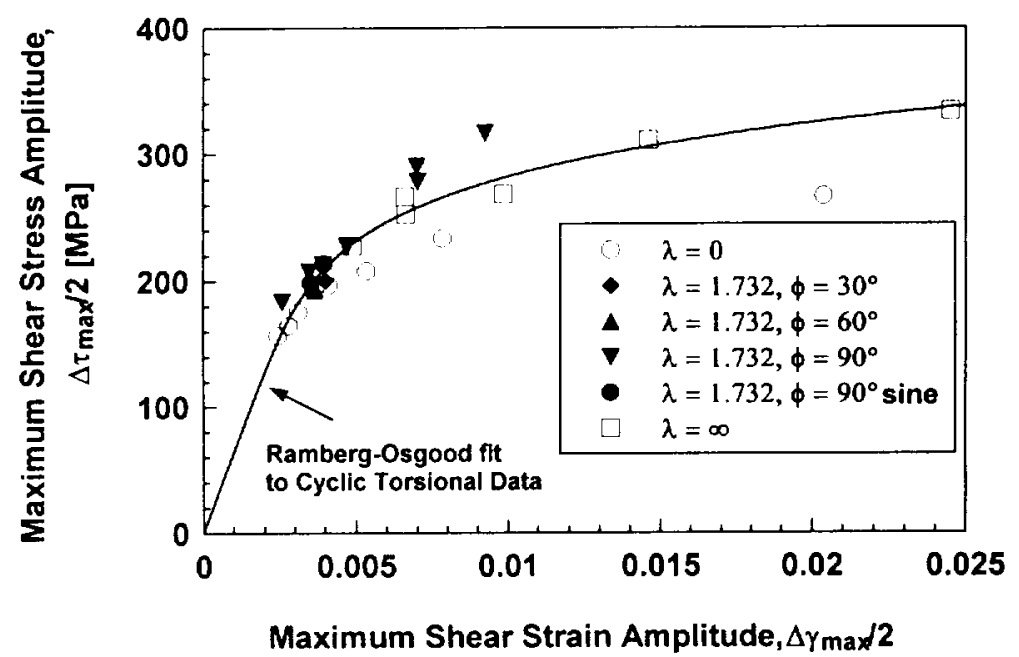

FlG. 18-Maximum shear stress-engineering shear strain (Tresca) data: out-of-phase experiments.

Table 3 contains constants for a Ramberg-Osgood type of cyclic stress-strain relation for the various loading conditions. The forms of these relations are

$$
\begin{aligned}
& \varepsilon=\frac{\sigma}{E}+\left[\frac{\sigma}{K^{\prime}}\right]^{1 / \prime^{\prime}} \text { for the axial stress-strain relation } \\
& \gamma=\frac{\tau}{G}+\left[\frac{\tau}{K^{\prime}}\right]^{1 / n i} \text { for the shear stress-strain relation }
\end{aligned}
$$

These constants were determined in a previous study $[18]$ by performing linear least squares fits to the logarithms of the near half-life stress amplitudes versus the logarithms of the near half-life inelastic strain amplitudes for each of the loading conditions listed in Table 3 . The axial and shear stresses corresponding to the axial and engineering shear strains of $0.5 \%$ are

\begin{tabular}{|c|c|c|c|c|c|c|c|}
\hline \multicolumn{2}{|c|}{$\begin{array}{l}\text { Loading } \\
\text { Parameters }\end{array}$} & \multicolumn{4}{|c|}{ Ramberg-Osgood Constants $^{a}$} & \multicolumn{2}{|c|}{ Stress at $0.5 \%$ Strain } \\
\hline$\phi$ & $\lambda$ & $K^{\prime}, \mathrm{MPa}$ & $n^{\prime}$ & $K_{,}^{\prime}, \mathrm{MPa}$ & $n_{\prime}^{\prime}$ & $\sigma, \mathrm{MPa}$ & $\tau, \mathrm{MPa}$ \\
\hline $0^{\circ}$ & 0 & 891 & 0.113 & & & 450 & \\
\hline $0^{\circ}$ & $\infty$ & & & 589 & 0.142 & & 232 \\
\hline $0^{\circ}$ & 1.73 & 1272 & 0.259 & 604 & 0.262 & 290 & 131 \\
\hline $90^{\circ}$ & 1.73 & 2571 & 0.238 & 1247 & 0.230 & 563 & 256 \\
\hline
\end{tabular}

TABLE 3-Ramberg-Osgood constants for axial and shear cyclic stress-strain curves under various loading conditions; Material: Haynes 188 at $760^{\circ} \mathrm{C}$.

"From Ref 18. 
also listed in Table 3 . In both the axial and shear cases, cyclic stresses are lower under in-phase loading $\left(\lambda=1.73, \phi=0^{\circ}\right)$ and higher under out-of-phase loading $\left(\lambda=1.73, \phi=90^{\circ}\right)$ than the stresses corresponding to the individual axial $(\lambda=0)$ or torsional $(\lambda=\infty)$ loading cases.

\section{Discussion}

The cycle-dependent hardening rate, as indicated by the normalized stress values for the inphase tests (Figs. 7 and 8), seems to be independent of any non-zero proportionality constant, $\lambda$. However, the normalized stress range in the axial $(\lambda=0)$ test exhibited a slightly higher cycle-dependent hardening rate than the three in-phase tests. Similar behavior was not observed in the normalized shear stress ranges. The reason for this difference in the axial and torsional hardening rates of the in-phase tests is not apparent at present. In the out-of-phase tests, both the axial and shear stress ranges exhibited similar cycle-dependent hardening patterns.

It can be seen in Figs. 11 through 14 that the phase angle, $\phi$, between the axial and engineering shear strain command waveforms has a substantial effect on the near half-life kinematic hardening behavior. The widths of both the axial and torsional hysteresis loops decrease markedly with each $30^{\circ}$ increment of phase angle. This can also be observed in Figs. 3 to 6 and 9 and 10, which show the decrease in the widths of the hysteresis loops and the corresponding increase in the axial and shear stress ranges as the phase angle increases from 0 to $90^{\circ}$. Other researchers have reported similar behavior under out-of-phase axial-torsional loading $[2,4,7,9]$. The additional hardening that occurs in the out-of-phase axial-torsional loading is attributable to crystallographic slip in multiple directions, which is caused by the rotation of the principal axes that occurs in out-of-phase loading $[2,9,19]$

The von Mises criterion is a good estimator of the cyclic in-phase deformation behavior of Haynes 188 at $760^{\circ} \mathrm{C}$. As can be seen in Fig. 15, all of the in-phase data fall on or just above the Ramberg-Osgood fit to the cyclic axial data $(\lambda=0)$. The torsional $(\lambda=\infty)$ von Mises equivalent data show the largest deviation from the Ramberg-Osgood fit with as much as a $10 \%$ higher stress amplitude at the same equivalent strain amplitude. The maximum shear stress-strain, or Tresca approach, however, almost always overestimates the amount of cyclic hardening in the in-phase and axial experiments (Fig. 16). In the worst instance, the axial maximum shear stress amplitude is overestimated by $18 \%$.

Both the von Mises and the Tresca approaches fail to adequately account for the extra hardening observed in the out-of-phase, axial-torsional experiments, especially those with a phase angle of $90^{\circ}$ (Figs. 17 and 18). The $90^{\circ}$ out-of-phase experiments exhibit as much as $20 \%$ more hardening than the Ramberg-Osgood fit to the cyclic axial data and as much as $15 \%$ more hardening than that estimated by the maximum shear stress-strain or Tresca approach. Kanazawa et al. [2] accounted for the additional hardening in the sinusoidal waveform, outof-phase axial-torsional experiments on $1 \% \mathrm{Cr}-\mathrm{Mo}-\mathrm{V}$ steel by using a rotation factor, which is a ratio of the shear strain range at $45^{\circ}$ from the maximum shear plane to the maximum shear strain range. This factor was an attempt to account for the movement of dislocations within and across multiple crystallographic slip systems in the material. They were able to correlate both the in- and out-of-phase cyclic deformation data to within the same scatter band by using the rotation factor in conjunction with the maximum shear stress-strain (Tresca) approach. For Haynes 188 at $760^{\circ} \mathrm{C}$, the von Mises equivalent stress-strain curve, at least for the in-phase data, appears to represent the cyclic deformation data better than the maximum shear stressstrain method. Therefore, a method based on the von Mises approach, with appropriate flow and hardening rules to account for the phase angle-dependent hardening, might be able to estimate the additional hardening observed in the out-of-phase tests. 


\section{Conclusions}

The cyclic deformation behavior of a wrought cobalt-base superalloy, Haynes 188 , has been investigated at $760^{\circ} \mathrm{C}$ under various axial-torsional loading conditions. The following conclusions were drawn from the study of hysteresis loops and cyclic hardening behaviors under different loading conditions.

1. Under in-phase (proportional) loading, the ratio of the imposed engineering shear to axial strain amplitudes had little or no effect on the relative amounts of cycle-dependent hardening in either the axial or shear directions.

2. In out-of-phase (non-proportional) loading, for a given ratio of engineering shear to axial strain amplitudes and phase angles ranging from 0 to $90^{\circ}$, similar cycle-dependent hardening trends were observed for the axial and shear stress ranges. However, on an absolute basis, the largest stresses were observed when the phase angle was $90^{\circ}$, and the smallest stresses were observed when the phase angle was $0^{\circ}$.

3. The amount of hardening exhibited by Haynes 188 at $760^{\circ} \mathrm{C}$ and the shapes of the axial and torsional hysteresis loops under out-of-phase axial-torsional loading were directly dependent on the phase angle between the axial and engineering shear strain waveforms.

4. The equivalent stress-strain curve (von Mises) adequately estimated the cyclic deformation behavior of Haynes 188 at $760^{\circ} \mathrm{C}$ under in-phase (proportional) axial-torsional loading. However, the von Mises equivalent stress-strain criterion was not able to accurately estimate the extra hardening in the out-of-phase (non-proportional) experiments.

5. The maximum shear stress-strain (Tresca) criteria did not adequately estimate either the in-phase or the out-of-phase axial-torsional cyclic deformation behavior of Haynes 188 at $760^{\circ} \mathrm{C}$.

6. When multiaxial loading conditions exist in a structure, the use of either the Von Mises or the Tresca Criterion to estimate the cyclic deformation behavior does not always yield the actual cyclic deformation behavior of the material, especially under out-of-phase loading.

\section{References}

(1) Brown, M. W. and Miller, K. J., "Biaxial Cyclic Deformation Behavior of Steels," Fatigue of Engineering Materials and Structures, Vol. 1, 1979, pp. 93-106.

12) Kanazawa, K. Miller, K. J., and Brown, M. W. "Cyclic Deformation of 1\% Cr-Mo-V Steel under Out-of-phase Loads," Fatigue of Engineering Materials and Structures, Vol. 2, 1979, pp. 217-228.

13) Garud. Y.S., "Prediction of Stress-Strain Response under General Multiaxial Loading," Mechanical Testing for Deformation and Model Development, ASTM STP 765. R. W. Rohde and J. C. Swearengen, Eds., American Society for Testing and Materials, Philadelphia, 1982, pp. 223-238.

14] Cailletaud, G., Kaczmarek, H., and Policella, H., "Some Elements on Multiaxial Behavior of 316L Stainless Steel at Room Temperature," Mechanics of Materials, Vol. 3, 1984, pp. 333-347.

[5] McDowell. D. L. and Socie, D. F., "Transient and Stable Deformation Behavior Under Cyclic Nonproportional Loading." Multiaxial Fatigue, ASTM STP 853, K. J. Miller and M. W. Brown, Eds.. American Society of Testing and Materials, Philadelphia, 1985, pp. 64-87.

[6] McDowell, D. L.. "An Experimental Study of the Structure of Constitutive Equations for Nonproportional Cyclic Plasticity," Journal of Engineering Materials and Technology, Vol. 107, 1985, pp. $307-315$.

17] Fatemi. A. and Stephens, R. I., "Cyclic Deformation of 1045 Steel Under In-Phase and 90 Degree Out-of-Phase Axial-Torsional Loading Conditions," Multiaxial Fatigue: Analysis and Experiments, SAE Publication AE-14. G. E. Lease and D. Socie, Eds., Society of Automotive Engineers, Inc., Warrendale, PA, 1989, pp. 139-147.

[8] Takashi, Y. and Ogata, T., "Description of Nonproportional Cyclic Plasticity of Stainless Steel by a Two-Surface Model," Journal of Applied Mechanics, Vol. 58. 1991, pp. 623-630. 
[9] Jayaraman, N. and Ditmars, M. M., "Torsional and Biaxial (Tension-Torsion) Fatigue Damage Mechanisms in Waspaloy at Room Temperature," International Joumal of Fatigue, Vol. 11, No. 5, 1989. pp. 309-318.

[10] Nickel Base Alloys, International Nickel Company, Inc.. New York, 1977.

[11] Bonacuse, P. J. and Kalluri, S. "Elevated Temperature Axial and Torsional Fatigue Behavior of Haynes 188," NASA TM 105396, AVSCOM TR-91-C-(045, June 1992.

[12] Kalluri, S. and Bonacuse, P. J., "In-Phase and Out-of-Phase Axial-Torsional Fatigue Behavior of Haynes 188 at $760^{\circ} \mathrm{C}$." Adicances in Multiaxial Fatigue, ASTM STP /191, D. L. McDowell and R. Ellis, Eds., American Society for Testing and Materials, Philadelphia, 1993, pp. 133-150.

113] Kalluri, S. and Bonacuse, P. J., "A Data Acquisition and Control Program for Axial-Torsional Fatigue Testing." Applicutiom of Automation Technology to Fatigut and Fracture Testing, ASTM STP 1092, A. A. Braun, N. E. Ashbaugh, and F. M. Smith, Eds., American Society for Testing and Materials, Philadelphia, 1990, pp. 269-287.

[14] Poynting, J. H., "On Pressure Perpendicular to the Shear Planes in Finite Pure Shears, and on the Lengthening of Loaded Wires when Twisted." Proceedings of the Roval Society. London, Series A Vol. 82, 1909, pp. 546-559.

15] Poynting. J. H., "Changes in Dimensions of Steel Wire when Twisted and Pressure of Distortional Waves in Steel." Proceedings of the Royal Society, London. Series A Vol. 86, 1912, pp. 543-561.

[16] Swift. H. W., "Length Changes in Metals under Torsional Overstrain," Engincering, Vol. 163, 1947. pp. 253-257.

[17] Wack, B., "The Torsion of a Tube (or a Rod): General Cylindrical Kinematics and Some Axial Deformation and Ratchetting Measurements," Acta Mechanica. Vol. 80. 1989, pp. 39-59.

[18] Kalluri, S. and Bonacuse, P. J. "High Temperature Axial-Torsional Fatigue Testing: Tubular Specimen Design Issues," presented at the Symposium on Experimental Methods for High Temperature Material Behavior Characterization during the 1992 ASME Applied Mechanics, Materials, and Aerospace Summer Meeting, Scuttsdale. Arizona, 28 April-1 May 1992. American Society of Mechanical Engineers, New York.

[19] Bonacuse, P. J. and Kalluri. S., "Axial-Torsional Fatigue: A Study of Tubular Specimen Thickness Effects," Journal of Testing and Evaluation, JTEVA. Vol. 21. No. 3. May 1993, pp. 160-167. 